\title{
Cytoreductive treatment patterns among US veterans with polycythemia vera
}

\author{
Shreekant Parasuraman ${ }^{*}$, Jingbo Yu', Dilan Paranagama', Sulena Shrestha² ${ }^{1}$ Li Wang ${ }^{2}$, Onur Baser ${ }^{2,3}$ \\ and Robyn Scherber ${ }^{4,5}$
}

\begin{abstract}
Background: Polycythemia vera (PV) is a myeloproliferative neoplasm associated with increased thrombotic and cardiovascular risk, which are key contributors to patient morbidity and mortality. The Veterans Health Administration $(\mathrm{VHA})$ is the largest integrative health network in the United States. Available data concerning patients with PV in this population are limited.
\end{abstract}

Methods: This retrospective observational study evaluated the characteristics, management, and outcomes of patients with PV in the VHA Medical SAS ${ }^{\circledR}$ Dataset (October 1, 2005, to September 30, 2012). Inclusion criteria were $\geq 2$ claims for PV (ie, PV diagnostic code was recorded) $\geq 30$ days apart during the identification period, age $\geq 18$ years, and continuous health plan enrollment from $\geq 12$ months before the index date until the end of follow-up. All data were analyzed using descriptive statistics.

Results: The analysis included 7718 patients (median age, 64 years; male, 98\%; white, 64\%). The most common comorbidities before the index date were hypertension (72\%), dyslipidemia (54\%), and diabetes (24\%); 33\% had a history of smoking. During the follow-up period (median, 4.8 years), most patients did not receive treatment with cytoreductive therapy, including phlebotomy (53\%), or antiplatelet agents, such as aspirin (57\%). The thrombotic and cardiovascular event rates per 1000 patient-years were 60.5 and 83.8, respectively. Among patients who received cytoreductive treatment, the thrombotic event rate was 48.9 per 1000 patient-years. The overall mortality rate was 51.2 per 1000 patient-years.

Conclusion: The notable rates of thrombotic and cardiovascular events observed in this analysis, even among patients receiving cytoreductive treatment, highlight the important unmet clinical needs of patients with PV in the VHA.

Keywords: Polycythemia vera, Thrombosis, United States Department of Veterans Affairs, Veterans Health Administration

\section{Background}

Polycythemia vera (PV) is a myeloproliferative neoplasm (MPN) [1] that affects $>140,000$ patients in the United States [2]. In the National Cancer Institute-sponsored Surveillance, Epidemiology, and End Results cancer registry, the incidence of PV per 100,000 persons increased with advancing age $(0.1$ for $<34$ years, 0.7 for $35-49$ years, 2.4 for $50-74$ years, and 5.3 for $>75$ years) and was higher for men (1.3 vs 0.8 for women) and whites (1.1 vs 0.7 for African Americans and 0.8 for other race groups) [3]. Analyses of PV patient populations have estimated that arterial and venous thrombotic

\footnotetext{
* Correspondence: sparasuraman@incyte.com

${ }^{1}$ Incyte Corporation, 1801 Augustine Cut-Off, Wilmington, DE 19803, USA

Full list of author information is available at the end of the article
}

events occur at rates of 7 to 21 and 5 to 20 per 1000 person-years, respectively [4-7]. Thrombotic and cardiovascular events are among the leading causes of death in patients with PV [8], contributing to lower overall survival compared with age- and sex-matched members of the general population [9].

The treatment goals for patients with PV focus primarily on preventing or managing thrombotic and bleeding complications [10]. The European Collaboration on Low-Dose Aspirin in Polycythemia Vera (ECLAP) study demonstrated that treatment with low-dose aspirin was associated with reduced risk of thrombotic events and death from cardiovascular causes [11]. Results from the Cytoreductive Therapy in Polycythemia Vera (CYTOPV) trial supported treatment with phlebotomy to

(c) The Author(s). 2018 Open Access This article is distributed under the terms of the Creative Commons Attribution 4.0 International License (http://creativecommons.org/licenses/by/4.0/), which permits unrestricted use, distribution, and reproduction in any medium, provided you give appropriate credit to the original author(s) and the source, provide a link to the Creative Commons license, and indicate if changes were made. The Creative Commons Public Domain Dedication waiver (http://creativecommons.org/publicdomain/zero/1.0/) applies to the data made available in this article, unless otherwise stated. 
maintain hematocrit levels $<45 \%$ and reduce the risk of cardiovascular events and deaths resulting from thrombotic or cardiovascular events [12]. In addition, some patients benefit from cytoreductive treatment with hydroxyurea [13], interferon- $\alpha$ [14], or ruxolitinib [15, 16]. Ruxolitinib was approved by the US Food and Drug Administration (FDA) in 2014 for patients with PV who have had an inadequate response to or are intolerant of hydroxyurea, and it remains the only pharmaceutical agent approved by the FDA for the PV setting [17].

Real-world data on patient characteristics and clinical management of patients with PV help inform the understanding of the population and identification of unmet clinical needs. The Veterans Health Administration (VHA), the largest integrated health-care system in the United States, maintains patient records for US veterans receiving care in Veterans Integrated Service Networks. This is the first study to describe the demographics, clinical characteristics, management, and thrombotic and cardiovascular event rates of patients with $\mathrm{PV}$ in the VHA population.

\section{Methods}

\section{Study design}

This retrospective, observational study analyzed longitudinal data from the VHA Medical SAS ${ }^{\oplus}$ Dataset catalogued between October 1, 2005, and September 30, 2012 (Fig. 1). The VHA data set included deidentified patientlevel data from 21 Veterans Integrated Service Networks linking inpatient, outpatient, pharmacy, laboratory, enrollment, and vital sign databases.

\section{Patients}

Patients who had $\geq 2$ claims (ie, diagnostic code was recorded) for PV (defined as International Classification of Diseases, Ninth Edition, Clinical Modification [ICD-9CM] code 238.4) $\geq 30$ days apart during the identification period (January 1, 2007, to December 31, 2009) were included in the analysis. Additional inclusion criteria were age $\geq 18$ years old on the index date (defined as the date of each patient's first claim with a PV diagnosis during the identification period) and continuous health plan enrollment with medical and pharmacy benefits from $\geq 12$ months before the index date (ie, pre-index period) until the end of follow-up. Patients were followed from the index date until the date of death, date of disenrollment, or end of the study period (September 30, 2012), whichever occurred first.

\section{Assessments and analyses}

Patient demographics at index were reported. Assessments of pre-index patient characteristics included comorbidities, mean Deyo-Charlson Comorbidity Index (a weighted score [range, 1-6] of disease severity calculated using 19 conditions) [18], mean Chronic Disease Score (an aggregate comorbidity measure based on medication use) [19], and patient histories of thrombotic and cardiovascular events.

Patient records were reviewed for PV treatments and concomitant medications received; hematocrit level and white blood cell (WBC) count measures; and thrombotic, cardiovascular, and mortality events that occurred between the index date and the end of the follow-up period. Among patients with evaluable laboratory data, the proportions of patients with elevated hematocrit and WBC counts were recorded at the pre-index period and annually during the follow-up period. Hematocrit levels $\geq 45 \%$ and WBC counts $\geq 11 \times 10^{9} / \mathrm{L}$ were considered elevated. Thrombotic and cardiovascular events were not mutually exclusive (acute myocardial infarction, ischemic stroke, and transient ischemic attack spanned both categories), and were identified by ICD-9-CM diagnosis codes recorded in patient claims (Additional file 1: Table S1).

All data were analyzed using descriptive statistics.

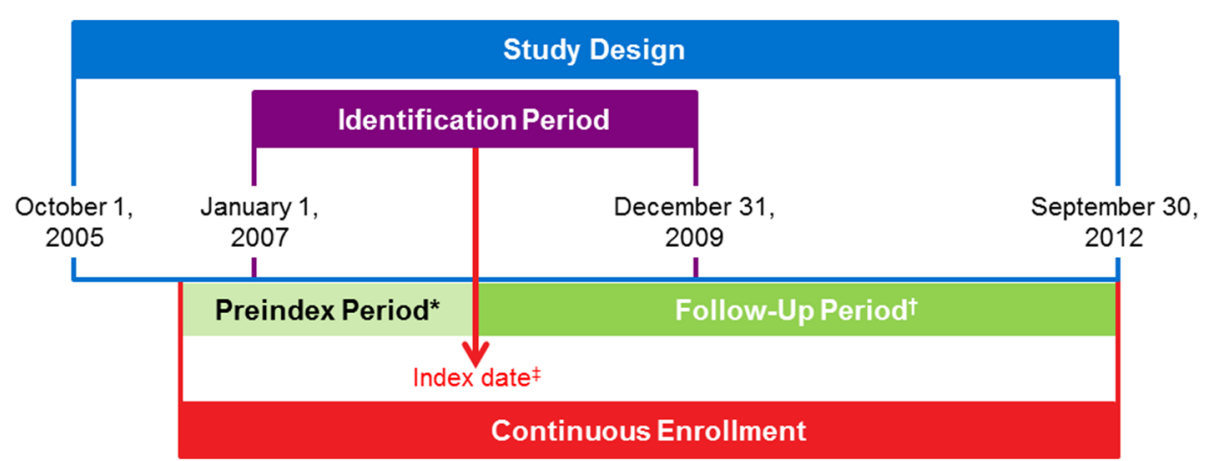

Fig. 1 Study design. PV, polycythemia vera. ${ }^{*} \geq 12$ months. ${ }^{\dagger}$ Patients were followed up from the index date until the date of the earliest event: death, disenrollment, or end of the study period. "The index date was defined as the date of each respective patient's first claim with a PV diagnosis during the identification period 


\section{Results}

Baseline patient demographic and clinical characteristics In all, 7718 patients with PV were included in the analysis. Most patients were $\geq 60$ years of age (70.7\%), male $(97.9 \%)$, and white $(63.9 \%$; Table 1$)$. Before the index date, hypertension (71.7\%), dyslipidemia (54.2\%), and diabetes $(24.0 \%)$ were the most common comorbidities. The mean (SD) Chronic Disease Score was 6.3 (4.2). A notable proportion of patients experienced thrombotic (arterial, 8.8\%; venous, $4.5 \%$ ) or cardiovascular (17.0\%) events within a year before the index date. Among patients with available laboratory data, $\geq 1$ elevated hematocrit level or WBC count was reported in $90.2 \%$ and $36.5 \%$ of patients, respectively, within a year before the index date. One third (33.1\%) of patients had a history of smoking.

\section{Laboratory values during follow-up}

The median duration of follow-up was 4.8 years. Among patients with available laboratory data, $\geq 1$ elevated hematocrit level was reported in $85.9 \%$ of patients during the first year of follow-up and in $91.6 \%$ by the end of follow-up (Table 2). The proportion of patients who experienced $\geq 1$ elevated WBC count was $34.4 \%$ during the first year of follow-up and $51.4 \%$ by the end of followup. Many patients experienced $\geq 2$ elevated hematocrit levels $(86.7 \%)$ or WBC counts (37.3\%) during follow-up.

\section{Cytoreductive therapy use during follow-up}

During follow-up, only $23.2 \%$ of patients had documentation of any pharmacologic cytoreductive treatment (Table 3). Among those who received cytoreductive therapy $(n=1787)$, hydroxyurea was used most often $(86.7 \%$ [1550/1787]). Only $32.8 \%$ of all patients had a record of treatment with phlebotomy, and more than half of all patients $(53.0 \%)$ had no record of cytoreductive treatment or phlebotomy. Overall, fewer than 1 in 10 patients (8.9\%) received both cytoreductive treatment and phlebotomy. The most common concomitant medications were antihypertensive agents and antilipid/anticholesterol agents, each received by a majority of patients; anticoagulants were received by $17.0 \%$ of patients (Table 3 ).

\section{Thrombotic and cardiovascular events during follow-up}

Thrombotic and cardiovascular events occurred in $22.9 \%$ and $30.1 \%$ of patients, respectively (Table 4 ). The rate of thrombotic events during follow-up was 60.5 per 1000 patient-years. Arterial thrombotic events were approximately twice as common as venous events; the most common arterial and venous thrombotic events were ischemic stroke $(10.7 \%)$ and deep vein thrombosis (6.9\%), respectively (Table 4 ). The rate of thrombotic events was 48.9 per 1000 patient-years among patients who received cytoreductive treatment before the event. Cardiovascular events
Table 1 Patient Demographics and Clinical Characteristics

\begin{tabular}{|c|c|}
\hline & $\begin{array}{l}\text { Patients With } \\
\text { PV }(N=7718)\end{array}$ \\
\hline \multicolumn{2}{|l|}{ Age at index date, ${ }^{a} y$} \\
\hline Mean (SD) & $65.9(11.3)$ \\
\hline Median (range) & $64(21-93)$ \\
\hline \multicolumn{2}{|l|}{ Age, n (\%) } \\
\hline $18-45$ y & $256(3.3)$ \\
\hline $46-59$ y & $2004(26.0)$ \\
\hline$\geq 60 y$ & $5458(70.7)$ \\
\hline \multicolumn{2}{|l|}{ Sex, n (\%) } \\
\hline Male & 7557 (97.9) \\
\hline \multicolumn{2}{|l|}{ Race/ethnicity, n (\%) } \\
\hline White & $4932(63.9)$ \\
\hline Black & $404(5.2)$ \\
\hline Hispanic & $275(3.6)$ \\
\hline Other ${ }^{b}$ & $134(1.7)$ \\
\hline Unavailable $^{c}$ & $1973(25.6)$ \\
\hline \multicolumn{2}{|l|}{ Comorbid conditions, pre-index ${ }^{a}$} \\
\hline Deyo-Charlson Comorbidity Index, mean (SD) & $1.4(1.7)$ \\
\hline Chronic Disease Score, mean (SD) & $6.3(4.2)$ \\
\hline \multicolumn{2}{|l|}{ Most frequent comorbidities, n (\%) } \\
\hline Hypertension & $5531(71.7)$ \\
\hline Dyslipidemia & $4181(54.2)$ \\
\hline Diabetes & $1851(24.0)$ \\
\hline Bleeding $^{d}$ & $669(8.7)$ \\
\hline Major & $512(6.6)$ \\
\hline Minor & $262(3.4)$ \\
\hline History of smoking, ${ }^{e} \mathrm{n}(\%)$ & $2551(33.1)$ \\
\hline \multicolumn{2}{|l|}{ Elevated, pre-index, ${ }^{a} n / N^{f}(\%)$} \\
\hline Hematocrit level & $5608 / 6214(90.2)$ \\
\hline WBC count & $2365 / 6477(36.5)$ \\
\hline \multicolumn{2}{|l|}{ Thrombotic events, ${ }^{\mathrm{d}}$ pre-index, ${ }^{\mathrm{a}} \mathrm{n}(\%)$} \\
\hline Arterial thrombosis & $681(8.8)$ \\
\hline Venous thrombosis & $349(4.5)$ \\
\hline Cardiovascular events pre-index, ${ }^{a}$ (\%) & $1315(17.0)$ \\
\hline
\end{tabular}

ICD-9-CM International Classification of Diseases, Ninth Edition, Clinical Modification, $P V$ polycythemia vera, $W B C$ white blood cell

aThe index date was defined as the date of each respective patient's first claim with a PV diagnosis during the identification period

${ }^{\mathrm{b}}$ Hawaiian or other Pacific Islander (0.8\%), Alaska native or American Indian (0.6\%), Asian (0.4\%)

'Missing $(21.1 \%)$, declined to answer (3.1\%), or unknown by patient $(1.4 \%)$ ${ }^{\mathrm{d}}$ Number of patients with $\geq 1$ event. Patients may be counted in $>1$ subcategory eSmoking status was determined through ICD-9-CM code 305.1, V15.82

${ }^{f}$ Elevated defined as hematocrit level $\geq 45 \%$, WBC count $\geq 11 \times 10^{9} / \mathrm{L} ; \mathrm{N}$ represents patients with evaluable laboratory data

occurred at a rate of 83.8 per 1000 patient-years. On average, the first thrombotic and cardiovascular events occurred 1.4 years after the index date. Overall, 1776 (23.0\%) patients died during follow-up, which was a mean 2.8 years 
Table 2 Patients With Elevated Hematocrit Levels and WBC Counts During the Follow-Up Period

\begin{tabular}{ll}
\hline${\text { Laboratory Value, } \mathrm{n} / \mathrm{N}(\%)^{\mathrm{a}}}^{\mathrm{a}}$ & Patients With PV \\
\hline$\geq 1$ elevated hematocrit level \\
12-month follow-up period & \\
24-month follow-up period & $5350 / 6230(85.9)$ \\
36-month follow-up period & $6167 / 6974(88.4)$ \\
48-month follow-up period & $6397 / 7115(89.9)$ \\
Entire follow-up period & $6492 / 7140(90.9)$ \\
$\geq 1$ elevated WBC count & \\
12-month follow-up period & $6544 / 7142(91.6)$ \\
24-month follow-up period & \\
36-month follow-up period & $2163 / 6280(34.4)$ \\
48-month follow-up period & $2851 / 6966(40.9)$ \\
Entire follow-up period & $3239 / 7113(45.5)$ \\
\hline
\end{tabular}

$P V$ polycythemia vera, $W B C$ white blood cell

${ }^{\mathrm{a}} \mathrm{N}$ represents patients with evaluable laboratory data

${ }^{\mathrm{b}}$ Defined as hematocrit $\geq 45 \%$

'Defined as WBC count $\geq 11 \times 10^{9} / \mathrm{L}$

after the index date. The mortality rate was 51.2 per 1000 patient-years (Table 4).

\section{Discussion}

In this analysis of 7718 patients diagnosed with PV in the VHA population, there was a substantial burden of thrombotic and cardiovascular events. During follow-up, nearly a quarter of patients had a thrombotic event, and almost one-third experienced a cardiovascular event. The thrombotic event rate (60.5 per 1000 patient-years) was higher than rates reported for cohorts of patients with PV in the general population (14.3 to 38 per 1000 patient-years) [5-7], even among high-risk patients (diagnosis before 2005, 40.1 per 1000 patient-years; after 2005, 29.3 per 1000 patient-years) [20].

There are several plausible contributors to the elevated thrombotic event rate in the VHA population. First, the VHA population may inherently have more risk factors for thrombotic events. Patients had a notable comorbid disease burden at baseline, and the prevalence of traditional cardiovascular risk factors such as hypertension, dyslipidemia, diabetes, and smoking [21] was high. Although not measured in our analysis, the prevalence of psychological comorbidities (eg, adjustment disorder, anxiety, depression, posttraumatic stress disorder, substance use disorder) [22] and other psychosocial issues (eg, homelessness) [23] are also elevated in the VHA patient population, which may complicate management of thrombotic and cardiovascular events. Finally, the catchment area overseen by VHA providers may be larger than the area covered by some traditional hematology providers, which could confound travel logistics and scheduling for some patients, thereby impeding some
Table 3 PV Treatment Patterns and Concomitant Medications During the Follow-Up Period

\begin{tabular}{|c|c|}
\hline Treatment, n (\%) & $\begin{array}{l}\text { Patients With } \\
\text { PV }(N=7718)\end{array}$ \\
\hline \multicolumn{2}{|l|}{ PV-related treatment ${ }^{\mathrm{a}}$} \\
\hline Pharmacologic cytoreductive treatment ${ }^{\mathrm{b}}$ & $1787(23.2)$ \\
\hline Hydroxyurea & $1550(20.1)$ \\
\hline Anagrelide & $206(2.7)$ \\
\hline Radiophosphorus & $132(1.7)$ \\
\hline Interferon or PEGylated interferon & $90(1.2)$ \\
\hline Busulfan & $15(0.2)$ \\
\hline Phlebotomy ${ }^{c}$ & $2531(32.8)$ \\
\hline $\begin{array}{l}\text { Pharmacologic cytoreductive } \\
\text { treatment and phlebotomy }\end{array}$ & $688(8.9)$ \\
\hline No cytoreductive treatment or phlebotomy & $4088(53.0)$ \\
\hline Aspirin $^{d}$ & $1815(23.5)$ \\
\hline Antiplatelet agents, not including aspirin & $1511(19.6)$ \\
\hline \multicolumn{2}{|l|}{ Common concomitant medications } \\
\hline Antihypertensive agents & $6671(86.4)$ \\
\hline ACE inhibitors & $4226(54.8)$ \\
\hline Antilipid/anticholesterol agents & $4882(63.3)$ \\
\hline Antidiabetic agents & $2163(28.0)$ \\
\hline Anticoagulants & $1313(17.0)$ \\
\hline Inotropic agents & $580(7.5)$ \\
\hline Antiarrhythmic agents & $362(4.7)$ \\
\hline
\end{tabular}

$A C E$ angiotensin-converting enzyme, $P V$ polycythemia vera

a Ruxolitinib received approval from the US Food and Drug Administration for patients with PV who have had an inadequate response to or are intolerant of hydroxyurea after the end of the study period

${ }^{b}$ Patients receiving pharmacologic cytoreductive treatment may have also received phlebotomy

${ }^{\mathrm{C}}$ Patients receiving phlebotomy may have also received pharmacologic cytoreductive treatment

Includes both prescribed and over-the-counter aspirin and may underrepresent actual aspirin use

standard practices (eg, frequent phlebotomy, coordination of care, obtaining outside laboratory tests) [24].

Although the care provided during the follow-up period may have been appropriate by the standards of the time, current standard practice based on more recent evidence may be associated with improved patient care. Of interest, 3 in 4 patients had no documentation of any pharmacologic cytoreductive treatment, and more than half had no documentation of pharmacologic cytoreductive treatment or phlebotomy. The low cytoreductive treatment rate in this population may explain why 9 in 10 patients had elevated hematocrit levels and 1 in 3 had elevated WBC counts. These findings are important; the CYTO-PV study indicated that elevated hematocrit and WBC counts were associated with increased risk of PV-related clinical complications [12, 25]. The cytoreductive treatment patterns observed in our study may be related to the available evidence at the time. For example, CYTO-PV study results 
Table 4 Thrombotic Events, Cardiovascular Events, and Deaths Occurring During the Follow-Up Period

\begin{tabular}{|c|c|c|c|c|c|}
\hline Event & $\begin{array}{l}\text { Patients With } \\
\geq 1 \text { Event, n (\%) }\end{array}$ & $\begin{array}{l}\text { Mean Time to } \\
\text { First Event, y }\end{array}$ & Patient-Years $^{\mathrm{a}}$ & $\begin{array}{l}\text { Event Rate, } \\
\text { per } 1000 \\
\text { Patient-Years }\end{array}$ & $\begin{array}{l}95 \% \mathrm{Cl} \text { of } \\
\text { Event Rate }\end{array}$ \\
\hline \multicolumn{6}{|l|}{ Among all patients with $\mathrm{PV}(\mathrm{N}=7718)$} \\
\hline Thrombotic event & $1771(22.9)$ & 1.4 & $29,276.2$ & 60.5 & $57.7-63.4$ \\
\hline Arterial & $1275(16.5)$ & 1.5 & $30,874.3$ & 41.3 & $39.1-43.6$ \\
\hline Ischemic stroke & $825(10.7)$ & 1.4 & $32,216.2$ & 25.6 & $23.9-27.4$ \\
\hline Transient ischemic attack & $344(4.5)$ & 1.6 & $33,609.5$ & 10.2 & $9.2-11.4$ \\
\hline Acute myocardial infarction & $224(2.9)$ & 2.3 & $34,167.1$ & 6.6 & $5.8-7.5$ \\
\hline Peripheral arterial thrombosis & $109(1.4)$ & 2.0 & $34,364.7$ & 3.2 & $2.6-3.8$ \\
\hline Venous & $678(8.8)$ & 1.4 & $32,621.4$ & 20.8 & $19.3-22.4$ \\
\hline Deep vein thrombosis & $535(6.9)$ & 1.4 & $32,992.0$ & 16.2 & $14.9-17.7$ \\
\hline Pulmonary embolism & $234(3.0)$ & 1.7 & $34,029.2$ & 6.9 & $6.1-7.8$ \\
\hline Superficial thrombophlebitis & $42(0.5)$ & 1.9 & $34,529.8$ & 1.2 & $0.9-1.7$ \\
\hline Cardiovascular event & $2325(30.1)$ & 1.4 & $27,750.5$ & 83.8 & $80.4-87.3$ \\
\hline Heart failure & $1442(18.7)$ & 1.5 & $30,730.4$ & 46.9 & $44.6-49.4$ \\
\hline Ischemic stroke & $825(10.7)$ & 1.4 & $32,216.2$ & 25.6 & $23.9-27.4$ \\
\hline Transient ischemic attack & $344(4.5)$ & 1.6 & $33,609.5$ & 10.2 & $9.2-11.4$ \\
\hline Acute myocardial infarction & $224(2.9)$ & 2.3 & $34,167.1$ & 6.6 & $5.8-7.5$ \\
\hline Unstable angina & $185(2.4)$ & 2.3 & $34,193.5$ & 5.4 & $4.7-6.3$ \\
\hline Percutaneous coronary intervention & $78(1.0)$ & 2.0 & $34,444.8$ & 2.3 & $1.8-2.8$ \\
\hline Coronary artery bypass graft & $7(0.1)$ & 2.0 & $34,624.2$ & 0.2 & $0.1-0.4$ \\
\hline Mortality & $1776(23.0)$ & 2.8 & $34,684.6$ & 51.2 & $48.9-53.6$ \\
\hline \multicolumn{6}{|c|}{ Among patients with PV receiving cytoreductive treatment $(n=1522)$} \\
\hline Thrombotic event & $295(19.4)$ & 2.2 & 6032.3 & 48.9 & $43.6-54.8$ \\
\hline \multicolumn{6}{|c|}{ Among patients with PV not receiving cytoreductive treatment $(n=6196)$} \\
\hline Thrombotic event & $1476(23.8)$ & 1.2 & $23,243.8$ & 63.5 & $60.3-66.8$ \\
\hline
\end{tabular}

PV polycythemia vera

${ }^{a}$ Up to the first respective event after diagnosis or end of the study period, whichever occurred first

${ }^{b}$ Rate per 1000 patient-years was defined as $1000 \times$ number of patients with first event/patient-years of total patients with PV

demonstrating the clinical benefit of hematocrit maintenance $<45 \%$ [12] and WBC counts $<11 \times 10^{9} / \mathrm{L}$ [25] were not published until after the study period of this analysis. However, some data concerning the clinical benefits of cytoreductive therapy, in particular hydroxyurea, predated the study period $[13,26]$. It is interesting that few patients had documented treatment with aspirin or other antiplatelet therapy. This may be a consequence of anticoagulant use or an artifact of low-dose aspirin being available over the counter (ie, may not be reflected in the medication dispensing forms). Findings from the ECLAP study published in 2004 demonstrated that low-dose aspirin reduced the risk of cardiovascular events in patients with PV [11]. Recent data suggest that patients with PV and hypertension who are treated with angiotensinconverting enzyme (ACE) inhibitors may require less cytoreductive treatment to control hematocrit levels compared with those who are treated with other antihypertensive agents [27]. The current analysis found that the majority of patients with PV received an ACE inhibitor during follow-up, but usage rates were similar regardless of cytoreductive treatment (data not shown). It may be important in future analyses to continue to report the association between ACE inhibitor and cytoreductive medication use on patient outcomes.

Of note, even among a subset of patients receiving cytoreductive treatment, the thrombotic and cardiovascular risk remained high. Approximately 1 in 4 patients treated with cytoreductive therapy experienced thrombotic events during follow-up, and nearly 1 in 3 had cardiovascular events. These data indicate an unmet clinical need in patients treated with traditional options and may in part explain why such a large proportion of patients were not receiving cytoreductive treatment during follow-up. 
Limitations of this analysis are primarily related to the retrospective study design and reliance on the accuracy of the database. The PV disease diagnosis, thrombotic events, and other clinical conditions were identified using ICD-9-CM codes, which are subject to potential miscoding (eg, cases of secondary polycythemia may have been logged as PV). Some PV-related treatments (eg, over-thecounter aspirin, phlebotomy at blood centers) may not have been recorded in the database and could have been underrepresented in our analysis. Gaps between patient visits could be long, during which time blood cell counts and other clinical measures were unavailable; this may have precluded an ability to observe long-term changes in a consistent group of patients. Only 1 WBC count $\geq 11 \times 10^{9} / \mathrm{L}$ was required for patients to have an elevated status, and it could have been caused by an acute illness. However, previous data suggest that this cutoff is important. In an analysis of the CYTO-PV study, WBC count $\geq 11 \times 10^{9} / \mathrm{L}$ was associated with a 3.9fold increased risk of major thrombosis compared with WBC count $<7 \times 10^{9} / \mathrm{L}(P=0.02)$ [25]. Furthermore, blood count analyses were incomplete because data were not available for an informative analysis of platelet counts. This VHA patient population was almost entirely male, precluding an analysis of treatment and management effects on thrombotic and cardiovascular events in female patients. Finally, the exploratory nature of the analysis precluded formal statistical analyses.

\section{Conclusions}

This retrospective analysis of the VHA population identified a substantial burden of thrombotic and cardiovascular events among 7718 patients with PV managed between 2005 and 2012, before publication of the CYTO-PV results. Approximately 9 in 10 patients had elevated hematocrit levels and 1 in 3 had elevated WBC counts, which may increase the risk of PV-related clinical complications. The prevalence of additional cardiovascular risk factors was high, placing this population at a greater risk for thrombotic events. Surprisingly, many patients did not have documented treatment with cytoreductive therapy or phlebotomy. Collectively, these data suggest that some patients with PV in the VHA have unmet clinical needs that may be ameliorated with the use of both traditional and targeted cytoreductive treatment options. Recent clinical practice guidelines from the National Comprehensive Cancer Network provide specific treatment recommendations based on PV disease severity and response history [28].

\section{Additional file}

Additional file 1: Table S1. Thrombotic and Cardiovascular Event Codes. This table presents the ICD-9-CM codes for thrombotic and cardiovascular events employed in the study. (PDF $61 \mathrm{~kb}$ )

\section{Abbreviations}

CYTO-PV: Cytoreductive Therapy in Polycythemia Vera; ECLAP: European Collaboration on Low-Dose Aspirin in Polycythemia Vera; FDA: US Food and Drug Administration; ICD-9-CM: International Classification of Diseases, Ninth Edition, Clinical Modification; MPN: Myeloproliferative neoplasm; PV: Polycythemia vera; SD: Standard deviation; VHA: Veterans Health Administration; WBC: White blood cell

\section{Acknowledgments}

Statistical programming was performed by Lu Li, MS (Statistical Programming Team Lead, STATinMED Research [Plano, TX]). Editorial assistance was provided by Cory Pfeiffenberger, PhD (Complete Healthcare Communications, LLC [West Chester, PA], a CHC Group Company), whose work was funded by Incyte Corporation.

\section{Funding}

The study and writing support were funded by Incyte Corporation. The study design and collection, analysis, and interpretation of data were conducted by the authors, some of whom are employees of Incyte Corporation.

\section{Availability of data and materials}

The dataset supporting the conclusions in this article is available from the US Veterans Health Administration. However, restrictions apply to the availability of these data, which were used under license for the current study, and so are not publicly available.

\section{Authors' contributions}

All authors participated in writing the manuscript and analyzing the study data. SP, JY, DP, and RS participated in designing the study research. SP, JY SS, LW, and OB participated in performing the study research. SS and RS conducted statistical analyses of the data. All authors read and approved the final manuscript.

\section{Ethics approval and consent to participate}

Not applicable: This retrospective database analysis used de-identified data. As such, Institutional Review Board (IRB) approval to conduct this analysis was not required. This analysis complies with the Health Insurance Portability and Accountability Act (HIPAA) of 1996 and its implementing regulations of Title 45 Code of Federal Regulations Parts 160 and 164 ("HIPAA Privacy and Security Rules").

\section{Competing interests}

SP, JY, and DP are employees and stockholders of Incyte Corporation. SS, LW and $\mathrm{OB}$ are employees and stockholders of STATinMED Research, which is a paid consultant of Incyte Corporation. RS has received honoraria from Novartis and Gilead.

\section{Publisher's Note}

Springer Nature remains neutral with regard to jurisdictional claims in published maps and institutional affiliations.

\section{Author details}

${ }^{1}$ Incyte Corporation, 1801 Augustine Cut-Off, Wilmington, DE 19803, USA. ${ }^{2}$ STATinMED Research, Plano, TX, USA. ${ }^{3}$ Center for Innovation \& Outcomes Research (CIOR), Columbia University, New York, NY, USA. ${ }^{4}$ Oregon Health and Sciences University, Portland, OR, USA. ${ }^{5}$ Department of Hematology and Oncology, Mayo Clinic, Scottsdale, AZ, USA.

Received: 10 August 2017 Accepted: 23 April 2018

Published online: 04 May 2018

\section{References}

1. Arber DA, Orazi A, Hasserjian R, Thiele J, Borowitz MJ, Le Beau MM, et al. The 2016 revision to the World Health Organization classification of myeloid neoplasms and acute leukemia. Blood. 2016;127:2391-405.

2. Mehta J, Wang H, lqbal SU, Mesa R. Epidemiology of myeloproliferative neoplasms in the United States. Leuk Lymphoma. 2014;55:595-600.

3. Deadmond MA, Smith-Gagen JA. Changing incidence of myeloproliferative neoplasms: trends and subgroup risk profiles in the USA, 1973-2011. J Cancer Res Clin Oncol. 2015;141:2131-8. 
4. Barbui T, Carobbio A, Rumi E, Finazzi G, Gisslinger H, Rodeghiero F, et al. In contemporary patients with polycythemia vera, rates of thrombosis and risk factors delineate a new clinical epidemiology. Blood. 2014;124:3021-3.

5. Marchioli R, Finazzi G, Landolfi R, Kutti J, Gisslinger H, Patrono C, et al. Vascular and neoplastic risk in a large cohort of patients with polycythemia vera. J Clin Oncol. 2005;23:2224-32.

6. Vannucchi AM, Antonioli E, Guglielmelli P, Rambaldi A, Barosi G, Marchioli R, et al. Clinical profile of homozygous JAK2 617V>F mutation in patients with polycythemia vera or essential thrombocythemia. Blood. 2007;110:840-6.

7. Goyal RK, Davis KL, Cote I, Mounedji N, Kaye JA. Increased incidence of thromboembolic event rates in patients diagnosed with polycythemia vera: results from an observational cohort study. Blood (ASH Annual Meeting Abstracts). 2014 abstract 4840.

8. Tefferi A, Rumi E, Finazzi G, Gisslinger H, Vannucchi AM, Rodeghiero F, et al. Survival and prognosis among 1545 patients with contemporary polycythemia vera: an international study. Leukemia. 2013;27:1874-81.

9. Hultcrantz M, Kristinsson SY, Andersson TM, Landgren O, Eloranta S, Derolf $A R$, et al. Patterns of survival among patients with myeloproliferative neoplasms diagnosed in Sweden from 1973 to 2008: a population-based study. J Clin Oncol. 2012;30:2995-3001.

10. Barbui T, Barosi G, Birgegard G, Cervantes F, Finazzi G, Griesshammer M, et al. Philadelphia-negative classical myeloproliferative neoplasms: critical concepts and management recommendations from European LeukemiaNet. J Clin Oncol. 2011;29:761-70.

11. Landolfi R, Marchioli R, Kutti J, Gisslinger H, Tognoni G, Patrono C, et al. Efficacy and safety of low-dose aspirin in polycythemia vera. N Engl J Med. 2004;350:114-24.

12. Marchioli R, Finazzi G, Specchia G, Cacciola R, Cavazzina R, Cilloni D, et al. Cardiovascular events and intensity of treatment in polycythemia vera. $\mathrm{N}$ Engl J Med. 2013;368:22-33.

13. Kiladjian JJ, Chevret S, Dosquet C, Chomienne C, Rain JD. Treatment of polycythemia vera with hydroxyurea and pipobroman: final results of a randomized trial initiated in 1980. J Clin Oncol. 2011;29:3907-13.

14. Hasselbalch HC. A new era for IFN-a in the treatment of Philadelphia-negative chronic myeloproliferative neoplasms. Expert Rev Hematol. 2011;4:637-55.

15. Vannucchi AM, Kiladjian JJ, Griesshammer M, Masszi T, Durrant S, Passamonti $F$, et al. Ruxolitinib versus standard therapy for the treatment of polycythemia vera. N Engl J Med. 2015;372:426-35.

16. Passamonti F, Griesshammer M, Palandri F, Egyed M, Benevolo G, Devos T, et al. Ruxolitinib for the treatment of inadequately controlled polycythaemia vera without splenomegaly (RESPONSE-2): a randomised, open-label, phase 3b study. Lancet Oncol. 2017;18:88-99.

17. JAKAFI ${ }^{\oplus}$ (ruxolitinib). Full Prescribing Information, Incyte Corporation, Wilmington, DE, USA, 2016.

18. Charlson M, Szatrowski TP, Peterson J, Gold J. Validation of a combined comorbidity index. J Clin Epidemiol. 1994;47:1245-51.

19. Von Korff M, Wagner EH, Saunders K. A chronic disease score from automated pharmacy data. J Clin Epidemiol. 1992;45:197-203.

20. Barbui T, Vannucchi AM, Carobbio A, Thiele J, Rumi E, Gisslinger $\mathrm{H}$, et al. Patterns of presentation and thrombosis outcome in patients with polycythemia vera strictly defined by WHO-criteria and stratified by calendar period of diagnosis. Am J Hematol. 2015;90:434-7.

21. Goff DC Jr, Lloyd-Jones DM, Bennett G, Coady S, D'Agostino RB Sr, Gibbons R, et al. 2013 ACC/AHA guideline on the assessment of cardiovascular risk: a report of the American College of Cardiology/American Heart Association task force on practice guidelines. J Am Coll Cardiol. 2014;63:2935-59.

22. Seal KH, Bertenthal D, Miner CR, Sen S, Marmar C. Bringing the war back home: mental health disorders among 103,788 US veterans returning from Iraq and Afghanistan seen at Department of Veterans Affairs facilities. Arch Intern Med. 2007;167:476-82.

23. Byrne T, Fargo JD, Montgomery AE, Roberts CB, Culhane DP, Kane V. Screening for homelessness in the Veterans Health Administration: monitoring housing stability through repeat screening. Public Health Rep. 2015;130:684-92.

24. Friedman SA, Frayne SM, Berg E, Hamilton AB, Washington DL, Saechao F, et al. Travel time and attrition from VHA care among women veterans: how far is too far? Med Care. 2015;53:S15-22.

25. Barbui T, Masciulli A, Marfisi MR, Tognoni G, Finazzi G, Rambaldi A, et al. White blood cell counts and thrombosis in polycythemia vera: a subanalysis of the CYTO-PV study. Blood. 2015;126:560-1.
26. Fruchtman SM, Mack K, Kaplan ME, Peterson P, Berk PD, Wasserman LR. From efficacy to safety: a Polycythemia Vera Study Group report on hydroxyurea in patients with polycythemia vera. Semin Hematol. 1997;34: 17-23.

27. Barbui T, Masciulli A, Ghirardi A, Carobbio A. ACE inhibitors and cytoreductive therapy in polycythemia vera. Blood. 2017;129:1226-7.

28. NCCN Clinical Practice Guidelines in Oncology: Myoproliferative Neoplasms v.1.2018. https://www.nccn.org/professionals/physician_gls/pdf/mpn.pdf. Accessed 4 Oct 2017.

\section{Ready to submit your research? Choose BMC and benefit from:}

- fast, convenient online submission

- thorough peer review by experienced researchers in your field

- rapid publication on acceptance

- support for research data, including large and complex data types

- gold Open Access which fosters wider collaboration and increased citations

- maximum visibility for your research: over $100 \mathrm{M}$ website views per year

At BMC, research is always in progress.

Learn more biomedcentral.com/submissions 